\title{
Results of an Evaluation Scheme to Improve Quality of Care at the Yaoundé Gyneco-Obstetric and Pediatric Hospital, Cameroon
}

Namanou Ines Emma Woks ${ }^{2}$, , Bih Immaculate $\mathrm{Geh}^{2}$, Samuel Lele Bomgni ${ }^{2}$, Julius Sama Dohbit $^{1,2}$, Willy Tafen ${ }^{2}$, Andreas Chiabi ${ }^{1,2}$, Assumpta Lucienne Bella ${ }^{1,2}$, Fru Fobuzshi Angwafo III $^{1,2}$

${ }^{1}$ Faculty of Medicine and Biomedical Sciences, University of Yaoundé I, Cameroon

${ }^{2}$ Yaoundé Gyneco-Obstetric and Pediatric Hospital (YGOPH), Cameroon

*Corresponding Author: Dr. Namanou Ines Emma WOKS, NO 1827; Street 1564; Ngousso; Yaoundé 5 , Yaounde Gyneco-Obstetric and Pediatric Hospital, Cameroon, E-mail: emmawoks@gmail.com

\begin{abstract}
Background: Delivering quality care is essential to Universal Health Coverage. Resolution AFR/RC45/R3 urges member states of the WHO Africa region to develop evaluation schemes for continuous improvement of the quality of care. Herein, we describe an experience in developing a quality assurance scheme at YGOPH.

Methods: Quality assessment was carried out twice yearly, from 2016 to 2019. A four-step process was employed. Facility-based indicators were developed and used to collect data from all units by the internal auditing team. Each unit was scored on 100 points including positive and negative remarks from evaluators and service providers. Multiple amendable errors by head nurses were cause for dissuasive action. Survey results were presented at hospital rounds and conferences to foster emulation of best practices.
\end{abstract}

Results: Since 2016, the overall quality score improved progressively from $60.52 \%$ at baseline to $79.61 \%$ in 2019. The most significant outcomes were the positive changes in process of care, attitude of staff and innovations. The number of services with optimal performance scores (above 80\%) for quality increased from three (12\%) to eleven (44\%) over the period.

Conclusion: The quality evaluation scheme enabled the hospital to be a safe and patient-centered structure, providing acceptable healthcare.

Keywords: Performance-Based Management, Quality of Care, Healthcare, Cameroon.

\section{Abbreviations}

ECG: Electrocardiography, EEG: Electroencephalography, IOM: Institute of Medicine, PBM: PerformanceBased Management, SDG: Sustainable Development Goal, SMS: Short Message Service, NBSR: Nursing Bedside Shift Report, UHC: Universal Health Coverage, WHO: World Health Organization,YGOPH: The Yaoundé Gyneco-Obstetric and Pediatric Hospital

\section{INTRODUCTION}

The Institute of Medicine (IOM) defines quality of health care as the degree to which health services for individuals or populations increase the likelihood of desired health outcomes and are consistent with current professional knowledge [1,2]. An influential framework put forth by this institute includes seven domains of quality health care. These are: safety, effectiveness, people-centeredness, timeliness, equity, integration of care and efficiency [3].

Universal health coverage (UHC) is recognized as a unifying platform for making progress on Sustainable Development Goal 3 for health..
Until recently, however, many countries efforts have focused more on essential health coverage and financial protection, and far less on quality - an equally important component of UHC [4, 5]. According to the World Health Organization (WHO), inadequacies in the quality of care provided in hospitals is responsible for poor progress in indicators of maternal and child health despite increased coverage [6]. Resolution AFR/RC45/R3 urges member states of the WHO regional committee for Africa to motivate their healthcare institutions to develop evaluation schemes for continuous improvement of quality of care. 
Results of an Evaluation Scheme to Improve Quality of Care at the Yaoundé Gyneco-Obstetric and Pediatric Hospital, Cameroon

Cameroon has a pyramidal health system. The Yaounde Gyneco-Obstetric and Pediatric Hospital (YGOPH) is a tertiary hospital, at the top of the health pyramid, specialized in maternal and child care. At the intermediate level, there are regional hospitals and district hospitals and health centers at the base. Maternal mortality has dropped from 669 per 100, 000 live births in 2004 to 596 per 100, 000 live births in 2015 [7,8]. The latest demographic and health survey puts it at 467 .

Audits done at the YGOPH between 2012 to 2013 militated for a change in the management strategy of the hospital to improve upon patient outcomes. To reduce hospital structural deficits and increase its efficiency, it was imperative to improve quality of care and services. This study sought to present and evaluate the quality assurance scheme at the YGOPH.

\section{MethodS}

\subsection{Indicators of the Quality Control Scheme}

Prior to implementation of the scheme, the assessment by the World Bank expert noted that despite staff surplus, services to users were of less than desired quality, drugs and consumables often out of stock and equipment broken down [9]. The quality improvement program was initiated in 2016 and is continuing. Quality of care was assessed once every semester; in July and December 2016, March and September 2017, April and September 2018 and April and November 2019. All 25 clinical and paraclinical units were evaluated at each session. See Table $l$ for the list of services and units at the hospital. The scheme was set-up using a four-step cycle.

Table 1. List of services and units at the Yaounde Gyneco-Obstetric and Pediatric Hospital (YGOPH)

\begin{tabular}{|l|l|}
\hline \multicolumn{1}{|c|}{ Services } & \multicolumn{1}{|c|}{ Units } \\
\hline Anesthesia and Reanimation & $\begin{array}{l}\text { Anesthesia } \\
\text { Reanimation }\end{array}$ \\
\hline Operating Theatre & $\begin{array}{l}\text { Theatre } \\
\text { Utilities room } \\
\text { Sterilization unit }\end{array}$ \\
\hline Pediatric Surgery & Pediatric surgery unit \\
\hline Gynecology and Obstetrics & $\begin{array}{l}\text { Maternity } \\
\text { Inpatient Gynecology unit } \\
\text { Outpatient Gynecology unit } \\
\text { Family Planning unit }\end{array}$ \\
\hline Pediatrics & $\begin{array}{l}\text { Outpatient Pediatric unit } \\
\text { Inpatient Pediatric unit I } \\
\text { Inpatient Pediatric unit II } \\
\text { Neonatology unit }\end{array}$ \\
\hline Emergency & Emergency unit \\
\hline Laboratory & $\begin{array}{l}\text { Radiology unit } \\
\text { Laboratory unit }\end{array}$ \\
\hline Anatomo-pathology & $\begin{array}{l}\text { EEG/ECG unit } \\
\text { Histopathology unit }\end{array}$ \\
\hline Ophthalmology/ Dentistry/ ENT & Ophthalmology/ Dentistry/ ENT \\
\hline Others & $\begin{array}{l}\text { Physical therapy } \\
\text { Acupuncture } \\
\text { Dermatology } \\
\text { Mortuary }\end{array}$ \\
\hline Pharmacy & Pharmacy \\
\hline
\end{tabular}

\subsection{Development}

The first step in the elaboration of a quality assurance scheme at the YGOPH was the creation of a steering committee in 2015. This committee consisted of head nurses from all nine clinical and paraclinical services in the hospital. Preliminary investigations in Cameroon revealed that no hospital had quality assessment programs. The indicators for quality assessment were developed and improved upon progressively from the first to the eighth survey. The line and senior nurse managers initially elaborated some quality indicators. Then, each nurse manager was urged to propose other relevant indicators [3]. See Table 2 for the exhaustive list of 28 indicators used. They were mostly related to the structure and process of care in different units. See supplementary file for grading sheets used to assess hospital units. 
Results of an Evaluation Scheme to Improve Quality of Care at the Yaoundé Gyneco-Obstetric and Pediatric Hospital, Cameroon

Table 2. Hospital Indicators of quality of care (IQC), the YGOPH, Cameroon, 2017

\begin{tabular}{|c|c|c|c|}
\hline Code & Indicator & $\begin{array}{l}\mathbf{N}^{\circ} \text { of } \\
\text { units }\end{array}$ & Names of units in which indicator was assessed \\
\hline IQC 1 & Handover of nursing shifts & 25 & \multirow[b]{2}{*}{$\begin{array}{l}\text { Acupuncture, Histopathology, Anesthesia, Theatre, Utilities } \\
\text { room, Pediatric Surgery, Dermatology, EEG/ECG, Outpatient } \\
\text { Gynecology Unit, Inpatient Gynecology Unit, laboratory, } \\
\text { maternity, mortuary, neonatology, } \\
\text { Ophthalmology/ENT/Dentistry, Outpatient Pediatrics unit, } \\
\text { Inpatient Pediatrics I and II, Pharmacy, Physiotherapy, Family } \\
\text { Planning, Radiology, Reanimation, Emergency, Sterilization }\end{array}$} \\
\hline IQC 2 & $\begin{array}{l}\text { Prevention of Hospital- } \\
\text { Acquired Infections (HAI) }\end{array}$ & 25 & \\
\hline IQC 3 & Quality of reception & 23 & \multirow{3}{*}{$\begin{array}{l}\text { Acupuncture, Histopathology, Anesthesia, Theatre, Pediatric } \\
\text { Surgery, Dermatology, EEG/ECG, Outpatient Gynecology } \\
\text { Unit, Inpatient Gynecology Unit, laboratory, maternity, } \\
\text { mortuary, neonatology, Ophthalmology/ENT/Dentistry, } \\
\text { Outpatient Pediatrics unit, Inpatient Pediatrics I and II, } \\
\text { Pharmacy, Physiotherapy, Family Planning, Radiology, } \\
\text { Reanimation, Emergency }\end{array}$} \\
\hline IQC 4 & Patient rights & 23 & \\
\hline IQC 5 & $\begin{array}{l}\text { Infection, Education, } \\
\text { Communication (IEC) }\end{array}$ & 23 & \\
\hline IQC 6 & $\begin{array}{l}\text { Transfer protocol for } \\
\text { patients/biological } \\
\text { samples respected }\end{array}$ & 14 & $\begin{array}{l}\text { Histopathology, Anesthesia, Theatre, Pediatric Surgery, } \\
\text { Outpatient Gynecology unit, Inpatient Gynecology unit, } \\
\text { laboratory, maternity, neonatology, Inpatient Pediatrics unit I } \\
\text { and II, Outpatient Pediatrics unit, Reanimation, , Emergency }\end{array}$ \\
\hline IQC 7 & Equipment maintainance & 14 & $\begin{array}{l}\text { Anesthesia, Utilities room, Theatre, Pediatric surgery, } \\
\text { laboratory, EEG/ECG, maternity, neonatology, } \\
\text { Ophthalmology/ENT/Dentistry, Inpatient Pediatrics unit I and } \\
\text { II, Radiology, Reanimation, Emergnecy, Sterilization }\end{array}$ \\
\hline IQC 8 & Vital parameters taken & 11 & $\begin{array}{l}\text { Pediatric surgery, Outpatient Gynecology, Inpatient } \\
\text { Gynecology, maternity, neonatology, Outpatient Pediatrics, } \\
\text { Inpatient Pediatrics, Family planning, Reanimation, } \\
\text { Emergency }\end{array}$ \\
\hline IQC 9 & Planning of nursing care & 10 & $\begin{array}{l}\text { Pediatric surgery, Inpatient Gynecology, maternity, } \\
\text { neonatology, Inpatient Pediatrics I and II, Reanimation, } \\
\text { Emergency, Acupuncture, Physiotherapy }\end{array}$ \\
\hline $\begin{array}{l}\text { IQC } \\
10\end{array}$ & Ward hygiene & 4 & Anesthesia, Theatre, Utilities room, Sterilization \\
\hline $\begin{array}{l}\text { IQC } \\
11\end{array}$ & Follow-up of samples & 2 & Histopathology, laboratory, \\
\hline $\begin{array}{l}\text { IQC } \\
12\end{array}$ & $\begin{array}{l}\text { Reception of } \\
\text { linen/instruments }\end{array}$ & 2 & Utilities room, Sterilization \\
\hline $\begin{array}{l}\text { IQC } \\
13\end{array}$ & Mastery of role as nurses & 1 & Theatre \\
\hline $\begin{array}{l}\text { IQC } \\
14 \\
\end{array}$ & $\begin{array}{l}\text { Washing and treatment of } \\
\text { linen }\end{array}$ & 1 & \multirow[t]{2}{*}{ Utilities room } \\
\hline $\begin{array}{l}\text { IQC } \\
15 \\
\end{array}$ & Transfer of linen & 1 & \\
\hline $\begin{array}{l}\text { IQC } \\
16\end{array}$ & $\begin{array}{l}\text { Paraclinical investigations } \\
\text { done }\end{array}$ & 1 & \multirow[t]{2}{*}{ EEG/ECG } \\
\hline $\begin{array}{l}\text { IQC } \\
17\end{array}$ & $\begin{array}{l}\text { Preparation of working } \\
\text { tools }\end{array}$ & 1 & \\
\hline $\begin{array}{l}\text { IQC } \\
18\end{array}$ & Partogram/checklist & 1 & Maternity \\
\hline $\begin{array}{l}\text { IQC } \\
19\end{array}$ & Distribution of tasks & 1 & \multirow[t]{3}{*}{ Mortuary } \\
\hline $\begin{array}{l}\text { IQC } \\
20\end{array}$ & $\begin{array}{l}\text { Organisation of wake } \\
\text { keeps }\end{array}$ & 1 & \\
\hline $\begin{array}{l}\text { IQC } \\
21\end{array}$ & Care of corpses & 1 & \\
\hline $\begin{array}{l}\text { IQC } \\
22\end{array}$ & Vaccination & 1 & Outpatient Pediatrics unit \\
\hline $\begin{array}{l}\text { IQC } \\
23\end{array}$ & Cash desk & 1 & Pharmacy \\
\hline
\end{tabular}


Results of an Evaluation Scheme to Improve Quality of Care at the Yaoundé Gyneco-Obstetric and Pediatric Hospital, Cameroon

\begin{tabular}{|l|l|c|c|}
\hline $\begin{array}{l}\text { IQC } \\
\mathbf{2 4}\end{array}$ & Dispensing of drugs & 1 & \\
\cline { 1 - 2 } $\begin{array}{l}\text { IQC } \\
\mathbf{2 5}\end{array}$ & ARV Dispensing point & 1 & \\
\cline { 1 - 2 } $\begin{array}{l}\text { IQC } \\
\mathbf{2 6}\end{array}$ & Cleaning and rinsing & 1 & Sterilization \\
\hline $\begin{array}{l}\text { IQC } \\
\mathbf{2 7}\end{array}$ & Packing and sterilization & 1 & \\
\cline { 1 - 2 } $\begin{array}{l}\text { IQC } \\
\mathbf{2 8}\end{array}$ & $\begin{array}{l}\text { Delivery of sterilized } \\
\text { equipment }\end{array}$ & 1 & \\
\hline
\end{tabular}
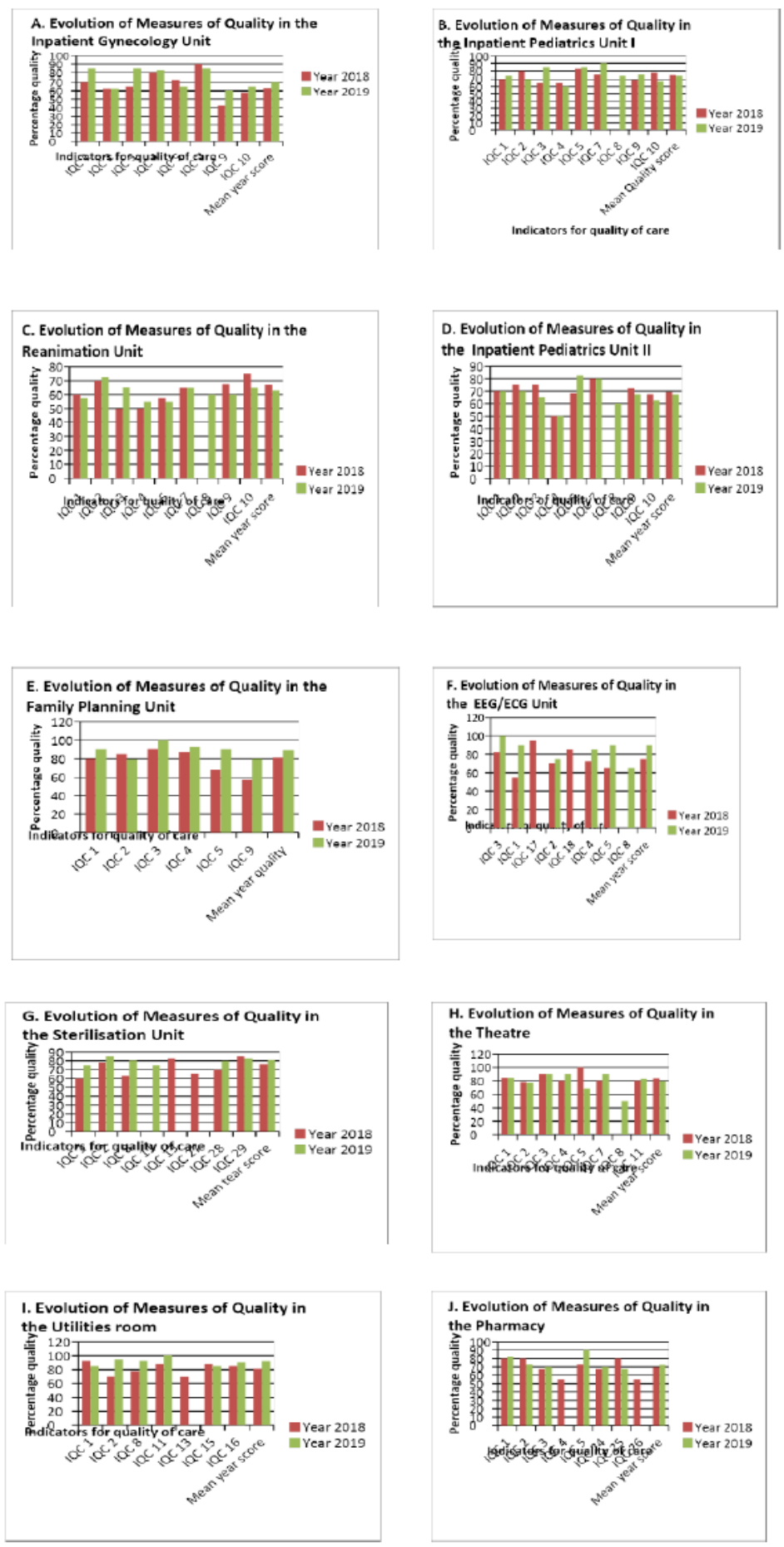

Figure 1. Indicators of quality of care overtime in the top-ranked and bottom-ranked service (10 services altogether) - See Table 2 for full meaning of indicator codes 
Results of an Evaluation Scheme to Improve Quality of Care at the Yaoundé Gyneco-Obstetric and Pediatric Hospital, Cameroon

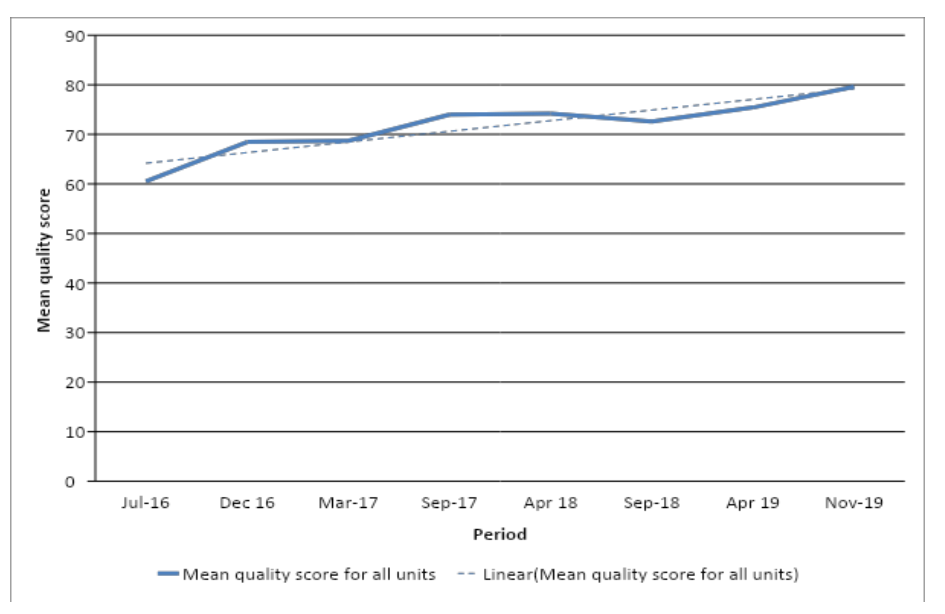

Figure 2. Trend in the quality of care in the YGOPH from 2016 to 2019

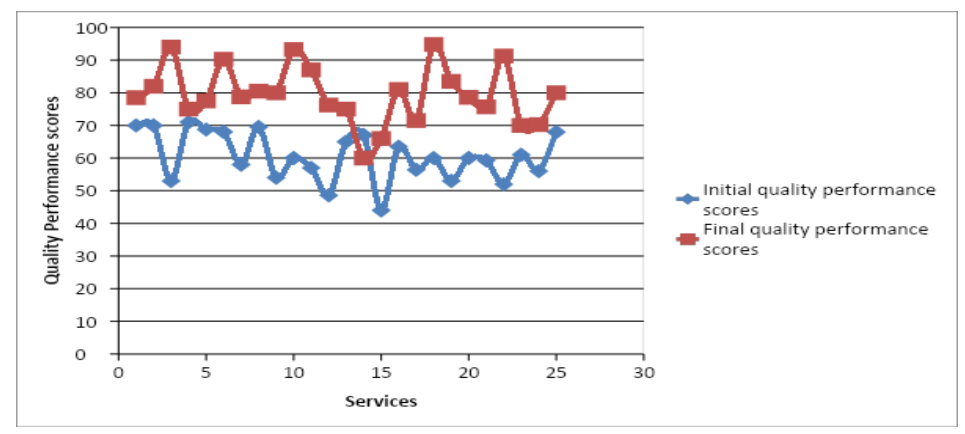

Figure 3. Comparison of initial and final quality performance scores

\subsection{Data Collection}

Prior to every assessment from 2016 to 2019, the committee was divided into five groups of three members each. These groups headed by a team leader, conducted biannual cross-sectional surveys in our facility. Each survey was carried out in three main phases.

\subsubsection{The Preparatory Phase}

In the preparatory phase of the survey, the steering committee held a working session five days prior to data collection. Roles and responsibilities for conducting the evaluation were discussed and validated.

\subsubsection{Data Collection and Evaluation}

Precautions were taken to ensure that the unit heads did not find themselves in the group assessing their unit, in respect of conflict of interest. During the first three surveys, data was collected in a six-column table (Indicator, positive remarks, drawbacks observed in healthcare, difficulties shared by personnel, recommendations and person in charge of implementing recommendations) while observing the healthcare providers on duty. From the $4^{\text {th }}$ to the $8^{\text {th }}$ assessment, an objective evaluation grid similar to that observed in Table
3 , was designed to minimize the differences in assessment between the teams. A total of 100 points was assigned to each unit. These points were shared between sub items allocated per indicator on the grading scale. The surveys were carried out in the mornings, from 7:30 a.m., during handover sessions in all units. Optimal quality of care was attained by services scoring above $80 \%$ during assessments.

\subsubsection{Report Writing}

At the end of the evaluation, remarks were shared with the team on duty and each team met thereafter to summarize findings for each service. Team reports were submitted to the senior nursing manager within 48 hours of the evaluation.

\subsubsection{Implementation of Corrective Strategies}

In addition to the service quality of care score, there were motivational incitors for the personnel. This motivated staff to engage in quality improvement activities, thereby contributing to improve care as reported by other authors [10]. Each evaluation team recorded problems identified in each unit. Urgent actions were proposed to the hospital management and unit heads to solve untoward events. Where errors were identified on two or 
more successive occasions and the service head nurse unable to correct, the result was lackluster performance. In such cases, the unit heads concerned were either replaced or lost bonuses allotted for optimal quality of care.

\subsubsection{Evaluation and Dissemination Of Results}

At coordination and the head nurses' monthly meetings, the personnel were coached on the primordial role of quality assurance. The results of the surveys were presented at these meetings and published in the hospital's newsletter, in order to foster hospital-wide emulation of best practices.

\section{RESUltS AND DISCUSSION}

The mean performance scores for quality of care which we calculated for all 25 units were $60.52 \%$ at baseline. This increased overtime and peaked at $79.61 \%$ by the $8^{\text {th }}$ survey, in November 2019. During the first survey, no unit performed optimally (scored at least $80 \%$ ) and the following shortcomings were identified: poor coordination of care across provider teams, limited patient autonomy, monotony in practice, non-existence and poor adherence to standards of care, checklists or evidence-based protocols and the absence of effective supervision of

healthcare providers [9]. To address these weaknesses, the new PBM approach was introduced to reorient resources and service delivery decisions. With the implementation of the quality evaluation scheme, the standard of care improved overtime. The units with the highest quality score at onset were Anesthesia and Theatre, both having $70.00 \%$. Although the quality of care was better in most units by December 2016, only three (Theatre, Pharmacy and EEG/ECG) out of 25 were efficient, scoring at least $80 \%$. This number dropped to two in the following survey. During the $4^{\text {th }}, 5^{\text {th }}, 6^{\text {th }}$ and $7^{\text {th }}$ assessments, 9/25, 7/25, 6/25 and 10/25 units demonstrated optimal quality in patient care. By the $8^{\text {th }}$ evaluation, eleven services performed well. These were: Theatre, Utilities room, Histopathology, Outpatient Pediatrics, Dermatology, Mortuary, Pediatric Surgery, EEG/ECG, maternity, Family planning and Physical therapy. Five units (Family planning, EEG/ECG, Sterilization, Theatre and Utilities room) had an exceptional performance, scoring $\geq 80 \%$ at least half of the time. Albeit, four units (Reanimation, Inpatient Gynecology, Inpatient Pediatrics I and II) were ranked least performing as their quality scores didn't reach the top quintile.

Table 3. Performance scores in quality of care in all 25 units at YGOPH between 2016 and 2019

\begin{tabular}{|c|c|c|c|c|c|c|c|c|c|}
\hline $\mathbf{N}^{\circ}$ & UNIT & $\begin{array}{c}\text { Baseline } \\
\text { 07/16 }\end{array}$ & $\begin{array}{c}1 \\
12 / 16\end{array}$ & $\begin{array}{c}2 \\
03 / 17\end{array}$ & $\begin{array}{c}3 \\
09 / 17\end{array}$ & $\begin{array}{c}4 \\
04 / 18\end{array}$ & $\begin{array}{c}5 \\
09 / 18\end{array}$ & $\begin{array}{c}6 \\
04 / 19\end{array}$ & $\begin{array}{c}7 \\
11 / 19\end{array}$ \\
\hline 1 & Anesthesia & 70 & 72.5 & 79.6 & 85 & 78.5 & 71.80 & 84 & 78.5 \\
\hline 2 & Theatre & 70 & 83.33 & 76.10 & 85 & 86 & 72.76 & 76.76 & 82 \\
\hline 3 & Utilities room & 53 & 67.5 & 50.11 & 85 & 90 & 72.95 & 90.24 & 94 \\
\hline 4 & Ophthalmo/Dentistry/ENT & 71 & 72 & 70.33 & 72.66 & 74.86 & 84.66 & 81.9 & 75 \\
\hline 5 & Acupuncture & 68.75 & 55.12 & 68 & 86.5 & 72.53 & 87.83 & 71 & 77.5 \\
\hline 6 & Histopathology & 68 & 37 & 76 & 75 & 57.69 & 54 & 58 & 90.25 \\
\hline 7 & Laboratory & 58 & 64 & 61 & 81.95 & 88.77 & 70.5 & 64.5 & 78.75 \\
\hline 8 & Sterilisation & 69.5 & 71.3 & 48.5 & 85 & 80 & 72.16 & 81.10 & 80.5 \\
\hline 9 & Outpatient Pediatrics & 54 & 68.51 & 65 & 67.75 & 63.5 & 74 & 75.47 & 80 \\
\hline 10 & Dermatology & 60 & 55.26 & 45 & 61.05 & 60.05 & 55 & 81 & 93.24 \\
\hline 11 & Mortuary & 57 & 68.91 & 73 & 79 & 77.5 & 73 & 89 & 87 \\
\hline 12 & Pharmacy & 48.6 & 87.5 & 62 & 50 & 75.92 & 63.5 & 68.5 & 76.25 \\
\hline 13 & Emergency Unit & 65 & 65.5 & 69.72 & 79.52 & 80 & 65 & 91.60 & 75 \\
\hline 14 & Radiology & 67 & 53 & 79.20 & 60.52 & 85 & 73 & 66 & 60 \\
\hline 15 & Reanimation & 44 & 74.80 & 53.8 & 55.19 & 70.09 & 63.50 & 60 & 66 \\
\hline 16 & Pediatric Surgery & 63.5 & 63 & 52 & 63.21 & 71 & 78.50 & 75.9 & 81 \\
\hline 17 & Inpatient Gynecology & 56.4 & 64 & 76 & 67.37 & 67 & 59 & 69 & 71.5 \\
\hline 18 & EEG/ECG & 60 & 86.5 & 81 & 88.55 & 76 & 74 & 85 & 94.8 \\
\hline 19 & Maternity & 53 & 77.27 & 72 & 76.85 & 78.57 & 83.18 & 65 & 83.5 \\
\hline 20 & Neonatalogy & 60 & 66.06 & 76 & 75.37 & 73.71 & 83.68 & 65 & 78.6 \\
\hline 21 & Outpatient Gynecology & 59.3 & 68.6 & 76.5 & 66.6 & 71.5 & 68 & 81.17 & 75.69 \\
\hline 22 & Family planning & 52 & 78.78 & 96 & 90.50 & 80.50 & 82 & 87 & 91.26 \\
\hline 23 & Inpatient Pediatrics I & 61 & 70 & 76 & 58.45 & 75.75 & 72 & 75 & 70 \\
\hline 24 & Inpatient Pediatrics II & 56 & 73 & 67 & 61.27 & 65.25 & 73.5 & 64.50 & 70.25 \\
\hline \multirow[t]{2}{*}{25} & Physical therapy & 68 & 68 & 78 & 92.10 & 55.75 & 86.83 & 79 & 80 \\
\hline & Mean score & 60.52 & 68.46 & 68.71 & 73.98 & 74.22 & 72.57 & 75.42 & 79.61 \\
\hline
\end{tabular}


The following innovations were introduced to improve quality as a result of the evaluations: antenatal care appointment reminders for pregnant women in the Outpatient Gynecology unit through Short Message Service (SMS); the institution of the Nursing Bedside Shift Report (NBSR) during handover in all clinical units [11]; conception and distribution of the patient's bill of rights; yearly randomized service rotation of nursing staff; replacement of persistently unproductive head nurses; the development of a handbook containing standard guidelines for nursing procedures; standard hand hygiene and disinfection procedures pasted in every unit; partnership with other health organizations such as Gifted mom, to improve access to vaccination services for children in the Outpatient Pediatrics unit $[12,13]$. Other initiatives were continuous pharmaceutical stock reporting as in the Ethiopian model [14]; white dashboards in every service to write daily patient care objectives and the introduction of kits for lifethreatening emergencies in the pharmacy and emergency units. These kits allow service providers to carry out life-saving interventions while payment is deferred. The implementation of recommendations and actions mentioned above explains quality improvement observed in the Mortuary where a protocol for care of corpses and staff uniforms were made available; and at Outpatient Pediatrics with the creation of nursing registers for optimal followup of care and vaccine monitoring systems.

Over the study period, new indicators were added especially at beginning of the learning curve as we constantly sought to improve quality assessments. Prior to the eighth survey, quality was almost stationary; so another strategy was introduced to ameliorate care consisting of following up the implementation of recommendations made during the $7^{\text {th }}$ survey. This significantly stepped up their execution, thereby further improving quality of care. Further, a smart definition of objectives and indicators that measure their attainment is important to maximize uniform grading and decrease subjectivity across teams and over the years. This work serves as an example of successful introduction of quality monitoring in resource limited settings. The inclusion of ratebased indicators will also ameliorate the quality assurance program [15,16]. Finally, external audits by neutral evaluators are being considered for future surveys.

\section{CONClusion}

The hospital staff have been progressively adapting to the changes made to improve quality, despite initial resistance. Systematic semester quality evaluations have been adopted in order to maintain good standards in healthcare and sustain staff engagement.

\section{Authors' CONTRIButions}

NIEW: data interpretation, write up of first manuscript, translation of research documents from French to English, literature search; BIG: introduction of the quality evaluation scheme at the YGOPH, conception of research project, manuscript revision ; SLB: study design, data collection; SLB: data analysis, manuscript revision; JSD: supervision of data collection and manuscript revision; WT: data analysis, manuscript revision; AC: manuscript revision; ALB: review and correction of work; AIIIFF: supervisor of the research work, correction of manuscript. All authors read and approved the final manuscript.

\section{ACKNOWLEDGEMENTS}

Thanks to Prof. Stephanie TOPP for her mentorship through the writing process. Thanks to the head nurses of the YGOPH for their contribution in the elaboration of care indicators.

\section{REFERENCES}

[1] Medicare I of M (US) C to D a S for QR and A in, Lohr KN. Defining Quality of Care [Internet]. National Academies Press (US); 1990 [cited 2019 Dec 31].

[2] Adindu A. Assessing and Assuring Quality of Health Care in Africa. Afr J Med Sci. 2010 Jan $1 ; 3$.

[3] Organization WH, OECD, Bank IB for R and DW. Delivering quality health services: a global imperative for universal health coverage [Internet]. World Health Organization; 2018 [cited 2019 Dec 31].

[4] Topp SM. The Lancet Global Health Commission on High Quality Health Systems - where's the complexity? Lancet Glob Health. 2017 Jun 1; 5(6):e571.

[5] Berwick DM. Lessons from developing nations on improving health care. BMJ. 2004 May 6; 328(7448):1124-9.

[6] WHO | What is Quality of Care and why is it important? [Internet]. WHO. [cited 2019 Dec 31]. Available from: http://www.who.int/ maternal_child_adolescent/topics/quality-ofcare/definition/en/ 
[7] Tebeu P-M, Halle-Ekane G, Da Itambi M, Mbu RE, Mawamba Y, Fomulu JN. Maternal mortality in Cameroon: a university teaching hospital report. Pan Afr Med J [Internet]. 2015 May 7 [cited 2020 Mar 21];21. A

[8] The DHS Program - Cameroon: Standard DHS, 2018 [Internet]. [cited $2020 \mathrm{Jul} 13$ ].

[9] From the brink of bankruptcy to a model for performance-based management: The story of one Yaoundé hospital [Internet]. [cited 2020 Jan 21].

[10] Fonyuy BE, Anchang PYK. Impact of the Performance-Based Financing Scheme on the Quality of Health-Care Delivery and Consumer Satisfaction in Health Districts in Cameroon. SciFed Nurs Healthc J [Internet]. 2017 Dec 15 [cited 2020 Jan 21];2(1). 11. Groves PS, Manges KA, Scott-Cawiezell J. Handing Off Safety at the Bedside. Clin Nurs Res. 2016 Oct 1;25(5):473-93.

[11] Manakongtreecheep K. SMS-reminder for vaccination in Africa: research from published, unpublished and grey literature. Pan Afr Med J. 2017;27(Suppl 3):23.

[12] Chiabi A, Nguefack FD, Njapndounke F, Kobela M, Kenfack K, Nguefack S, et al. Vaccination of infants aged 0 to 11 months at the Yaounde Gynaeco-obstetric and pediatric hospital in Cameroon: how complete and how timely? BMC Pediatr. 2017 Dec 19;17(1):206.

[13] McNatt Z, Linnander E, Endeshaw A, Tatek D, Conteh D, Bradley EH. A national system for monitoring the performance of hospitals in Ethiopia. Bull World Health Organ. 2015 Oct 1;93(10):719-26.

[14] Mainz J. Defining and classifying clinical indicators for quality improvement. Int $\mathrm{J}$ Qual Health Care J Int Soc Qual Health Care. 2003 Dec;15(6):523-30.

[15] Pinto VR, Ferreira SCM. Indicators for the assessment of the quality of nursing care: a descriptive-exploratory study. Online Braz J Nurs. 2017 Oct 9;16(2):140-51.

Citation: Namanou Ines Emma Woks et al.Results of an Evaluation Scheme to Improve Quality of Care at the Yaoundé Gyneco-Obstetric and Pediatric Hospital, Cameroon. ARC Journal of Public Health and Community Medicine. 2020; 5(2):39-46. DOI: dx.doi. org /10.20431/2456-0596.0502005.

Copyright: (C) 2020 Authors. This is an open-access article distributed under the terms of the Creative Commons Attribution License, which permits unrestricted use, distribution, and reproduction in any medium, provided the original author and source are credited. 